Revista lus et Praxis, Año 20, No 2, 2014, pp. 495 - 524

ISSN 0717 - 2877

Universidad de Talca - Facultad de Ciencias Jurídicas y Sociales

"Derechos humanos en tanto derechos morales:

dos concepciones"

Johnny Antonio Dávila

Colaboración recibida el 10 de abril y aprobada el 21 de mayo de 2014

Derechos humanos en tanto derechos morales: dos concepciones

JohnNy ANTONIO DÁVILA*

\title{
1. Introducción
}

La idea de los derechos humanos se ha visto confrontada con diferentes interrogantes. Una de ellas implica la búsqueda de aquello que les da validez o legitimidad, es decir, se trata de la pregunta sobre la posibilidad y la manera de fundamentar estos derechos. Un segundo interrogante, tan importante como el primero, atiende al hecho de cómo deben ser entendidos los derechos humanos, lo que equivale en sí a preguntar por su concepto. Desde una perspectiva analítica, las dos preguntas pueden acarrear estudios separados, aunque de hecho la segunda tiene una cierta prioridad sobre la primera, pues es menester tener claro sobre qué se habla, para luego determinar el fundamento de eso sobre lo que se habla. En este sentido, el objeto del presente estudio lo constituye la pregunta acerca de cómo deben ser conceptualizados los derechos humanos, sin pretender desdeñar la relación que pueda existir entre las ideas de concepto y fundamentación'.

El escrito está dividido en tres partes. La primera expone de manera sucinta la noción de derechos humanos, haciendo hincapié en el sentido prejurídico de los mismos, y básicamente en su sentido moral. Así, se introduce la idea de los derechos humanos en tanto derechos morales. A los efectos de sopesar el calibre de esta idea, se presentan los cuestionamientos que Jürgen Habermas ha expuesto contra la misma, al tiempo que se muestran las debilidades de tales cuestionamientos. La segunda parte constituye lo que sería propiamente el núcleo del estudio. Aquí se explica que en el ámbito filosófico se han desarrollado dos maneras diferentes de comprender los derechos humanos en tanto derechos

Profesor asistente de la Universidad Antonio Nariño (Bogotá, Colombia). Doctor en Filosofía (GeorgAugust-Universität Göttingen, Alemania).Correo electrónico: joandav31@yahoo.com, johnny.davila@ uan.edu.co.

${ }^{1}$ Carlos Peña y Luis Villavicencio sostienen una opinión similar en cuanto a la conexión entre concepto y fundamentación en materia de derechos humanos. Véanse PEÑA, Carlos (1992): "Sobre el concepto y fundamento de los derechos humanos", en: Derecho y Humanidades ( $\left.N^{\circ} 1\right)$, pp. 45-46 y VILLAVICENCIO, Luis (2008): “¿Derechos humanos para quiénes? Reflexiones sobre algunas cuestiones embarazosas", en: Revista de Derecho (Volumen 21, № 2), p. 34. 
morales y se indican los aspectos que las caracterizan. De igual manera, se dan a conocer los puntos problemáticos que están contenidos en dichas posiciones. Finalmente, la tercera parte alude a una posible comprensión de los derechos humanos que intenta superar los puntos críticos de las dos concepciones expuestas en la segunda parte, pero teniendo siempre como ámbito conceptual la idea de los derechos morales.

\section{Derechos humanos: iusnaturalismo y derechos morales}

Dentro de la literatura filosófica y jurídica, además de afirmarse casi con rotundidad que los derechos humanos son universales ${ }^{2}$, también se dice que son no legales. Que los mismos no sean legales significa que ellos existen y son válidos, independientemente de si están contenidos o no en el sistema jurídico positivo correspondiente, ya sea que se trate de un sistema estatal en particular o de un sistema jurídico positivo de índole internacional. La idea de fondo es la siguiente: la existencia y legitimidad de los derechos humanos no está sujeta ni a la voluntad de los Estados, ya sea en su esfera de acción nacional o internacional, ni a la de ningún otro organismo jurídico o político. Sin excluir que también hay opositores, debe decirse que esta idea de la no juridicidad de los derechos humanos ha tenido una buena acogida en el pensamiento político, jurídico y moral contemporáneos. El éxito de su recepción, sin embargo, no es similar al de su claridad conceptual. Dicho de manera más precisa, no existe unanimidad acerca de qué significa que los derechos humanos sean derechos no legales, por lo que existen múltiples enfoques que aspiran a aclarar qué es lo que se quiere decir con ello. Una elucidación en esta temática se hace necesaria por diversas razones. En primer lugar, por motivos conceptuales, pues el peso específico acerca de cómo deben ser comprendidos los derechos humanos recae justamente en su distanciamiento conceptual con respecto a los derechos legales. Pero, en segundo lugar, también hay razones prácticas, dado

\footnotetext{
2 A manera de ejemplo, véanse KüHNHARDT, Ludger (1987): Die Universalität der Menschenrechte. Studie zur ideengeschichtlichen Bestimmung eines politischen Schlüsselbegriffs (München, Günter Olzog Verlag), p. 113; KOLLeR, Peter (1998): "Der Geltungsbereich der Menschenrechte", en: coordinadores Stefan Gosepath y Georg Lohmann, Philosophie der Menschenrechte (Frankfurt del Meno, Suhrkamp), p. 97; ALEXY, Robert (1998): "Die Institutionalisierung der Menschenrechte im demokratischen Verfassungsstaat", en: coordinadores Stefan Gosepath y Georg Lohmann, Philosophie der Menschenrechte (Frankfurt del Meno, Suhrkamp), p. 246; HöfFE, Otfried, (1998): "Transzendentaler Tausch. Eine Legitimationsfigur für Menschenrechte?", en: coordinadores Stefan Gosepath y Georg Lohmann, Philosophie der Menschenrechte (Frankfurt del Meno, Suhrkamp), p. 29; SEN, Amartya (2004): "Elements of a Theory of Human Rights", en: Philosophy and Public Affairs (Volumen 32, № 4), pp. 315-317; CaSALs, María A. (2009): "El consenso y el margen de apreciación en la protección de los derechos humanos", en: Ius et Praxis (Volumen 15, No 1), pp. 296-297; Etzlonı, Amitai (2010): "The Normativity of Human Rights Is Self-Evident", en: Human Rights Quarterly (Volumen 32, № 1), p. 17 y MARTIN, Rex (2013): "Human Rights and the Social Recognition Thesis", en: Journal of Social Philosophy (Volumen 44, No 1), p. 1.
} 
que tales derechos forman un componente normativo irrenunciable de nuestro actuar social, y mal se estaría si se niega la importancia que tiene conocer los conceptos e ideas que rigen nuestra vida diaria. La claridad sobre el concepto incide, entonces, sobre el adecuado actuar social.

Actualmente disponemos sobre todo de dos concepciones que se nos muestran como candidatas para disipar las brumas que están presentes en este asunto. Una de ellas está representada por la tradición del pensamiento iusnaturalista. De acuerdo con éste, los derechos humanos son derechos no legales, por cuanto son el producto de un sistema normativo previo que es diferente del sistema normativo organizado institucionalmente. Este orden normativo previo suele recibir la denominación general de naturaleza, con lo que se afirmaría que los derechos humanos tienen su fuente en la naturaleza y no en la voluntad estatal o en la voluntad de entes de corte internacional, comunitario, etc. Y esta naturaleza sería la razón última por la cual los derechos humanos son derechos no legales. El problema es que por naturaleza se han entendido diferentes cosas dentro de la concepción del derecho natural. De esta suerte, algunas veces naturaleza quiere decir razón, con lo que cabría decir que los derechos humanos se caracterizan por su racionalidad, así como que su fuente es la razón ${ }^{3}$. Otras veces también se ha empleado naturaleza en tanto algo menos racional y más biológico ${ }^{4}$, por lo que se suele afirmar que los derechos humanos tienen su base en algo un poco más instintivo o biológico, y allí debería radicar su diferenciación con los derechos positivos. En un tercer sentido, naturaleza tiene una connotación religiosa, de donde se desprende que los derechos humanos no son derechos legales, precisamente debido a tal linaje divino, y que su fuente es un $\operatorname{dios}^{5}$.

\footnotetext{
${ }^{3}$ Ejemplo paradigmático del iusnaturalismo racional es la filosofía jurídica de Immanuel Kant. Véase, por ejemplo, KANT, Immanuel (1968 [1797]): Die Metaphysik der Sitten (Frankfurt del Meno, Suhrkamp), $\S A$ y $\S B$.

${ }^{4}$ Este es el caso del derecho natural de tendencia hobbesiana. Es cierto que Thomas Hobbes habla de leyes de la naturaleza que son dictadas por la razón, pero su idea concreta no es que la razón, a través de las leyes de la naturaleza, ordena algo que se debe hacer, sino que establece algo que es conveniente hacer para satisfacer necesidades y deseos connaturales (véanse HoBBEs, Thomas (2011 [1651]): Leviatán o la materia, forma y poder de una república eclesiástica y civil (Buenos Aires, Fondo de Cultura Económica), capítulos XIV y XV; RawLs, John (2009): Lecciones sobre la historia de la filosofía política (Barcelona, Paidós), pp. 99-101 y SORReLL, Tom (2007): "Hobbes's Moral Philosophy", en: coordinadora Patricia Springborg, The Cambridge Companion to Hobbes's Leviathan ( New York, Cambridge University Press), p. 132). Puede verse que el punto central de esta versión del iusnaturalismo no es la razón, sino "ciertos rasgos o características comunes, biológicas, psicológicas, sociales, etcétera, del ser humano, en las que deben buscarse el origen y raíz del derecho natural" (MAYNEZ, García (1993): Positivismo jurídico, realismo sociológico e iusnaturalismo (México, D. F., Fontamara), p. 132). En consecuencia, no puede decirse que Hobbes asume un criterio iusnaturalista estrictamente racional; más bien tiende hacia una versión biologicista.
}

${ }^{5}$ Aquí se está en presencia del derecho natural tomista. A modo de ejemplo, véase una posición similar en VöGELE, Wolfgang (1999): "Christliche Elemente in der Begründung von Menschenrechten", 
A pesar de su abolengo histórico e intelectual y de los relevantes servicios que ha prestado a la sociedad en tanto patrón de crítica, el iusnaturalismo tiene serias dificultades para dar cuenta de un concepto pertinente de los derechos humanos. Como primer punto cuestionable, vale decir que cada una de las tres formas en que suele emplearse la palabra naturaleza presenta ciertas particularidades que la hacen insuficiente. Naturaleza vista como razón da a entender que los derechos humanos en tanto naturales, a diferencia de los legales, son racionales. Un criterio diferenciador como éste no es del todo adecuado, pues dentro del sistema jurídico -contemporáneo- prima lo racional ${ }^{6}$. Por ejemplo, los procesos participativos establecidos por el Estado para la elaboración de normas son una representación de lo racional. El criterio biologicista de naturaleza es también a todas luces rechazable, lo que se debe a que en la noción de los derechos humanos, al igual que en la de los derechos legales, está latente un alto componente de racionalidad. La versión religiosa está lastrada con un impedimento conceptual particular: en razón de que cada religión puede fundamentar los derechos humanos desde sus propias creencias -las cuales pueden llegar a ser y son de hecho muy disímiles-, esta visión no ofrece una base conceptual suficientemente estable, o sea, podrían existir tantos conceptos de derechos humanos como religiones hay ${ }^{7}$.

Como segundo punto, aparte de las especificidades que se acaban de mencionar, a los tres sentidos de naturaleza empleados por el iusnaturalismo les es común el hecho de que centran su atención en ciertos aspectos que tienden a colocar al ser humano en tanto ente autónomo en segundo plano. Recurrir primordialmente a un dios, a la razón o a lo biológico para dar un concepto de derechos humanos equivale a dejar de lado aquello que es su punto medular, al ser humano. Esto resta fiabilidad al concepto resultante. En este orden de ideas, es de mencionarse que asumir una comprensión iusnaturalista de los derechos humanos, así como se ha entendido en este escrito, puede dar lugar a que se entienda que entes ajenos a lo humano -por ejemplo, ángeles o el cosmos- puedan ser titulares de tales derechos ${ }^{8}$. No se está negando ni afirmando que sea imposible que algo extraño a lo humano posea derechos,

en: coordinador Hans-Richard Reuter, Ethik der Menschenrechte. Zum Streit um die Universalität einer Idee (Tübingen, Mohr Siebeck), p. 113.

${ }^{6}$ Evidentemente, queda por discutir qué es racional y qué es la razón. No obstante, por motivos de espacio dejaremos esta temática abierta.

7 Para mayores detalles en relación con la problemática de la concepción religiosa de los derechos humanos, véase DÁvILA, Johnny Antonio (2013): "La universalidad de los derechos humanos y su fundamentación absoluta. Una visión crítica", en: Analecta Política (Volumen 3, № 4), pp. 38-43.

${ }^{8}$ Véase Pogge, Thomas (2011): Weltarmut und Menschenrechte (Berlin/New York, De Gruyter), pp. $72-$ 75. 
pero ello parece contradecir el que los derechos humanos atienden solo a lo humano. En tercer lugar, y partiendo de las ideas de Luis Villavicencio, debe decirse que la doctrina del derecho natural en general está afectada internamente por un problema metodológico -que a su vez es un problema argumentativo-, el cual menoscaba considerablemente la fortaleza que pueda tener esta concepción. El mentado problema yace en que el iusnaturalismo incurre en la Ilamada falacia naturalista, por cuanto que partiendo de enunciados estrictamente descriptivos (por ejemplo, la sencilla afirmación de la existencia de la razón o de determinados elementos biológicos), finalmente deriva en la propuesta de enunciados normativos ${ }^{9}$.

Las insuficiencias del iusnaturalismo nos conminan a explorar si es posible que los derechos humanos sean concebidos desde una perspectiva diferente. Y es aquí donde emerge la segunda concepción contemporánea -plausible- a la que se puede acudir para tal fin. En este caso se está haciendo alusión a la tesis de los derechos humanos en tanto derechos morales o como una subespecie de los derechos morales ${ }^{10}$. Derechos morales son derechos subjetivos a los que corresponde una determinada obligación y una determinada sanción, en caso de que se incumpla con el deber constituido, pero que no gozan necesariamente de apoyo por parte del aparato institucional, trátese del Estado u otros entes con funciones similares que existen, por ejemplo, en la esfera internacional. Dicho de otra manera, los derechos humanos, en tanto que son concebidos como derechos morales, existen y su respeto es exigible desde el ángulo de la moral, aunque ni los Estados ni la comunidad internacional los reconozcan como derechos legales. En comparación con el iusnaturalismo, esta postura tiene un marcado énfasis en lo humano, así que los derechos morales son asumidos como un producto humano, lo que resulta del hecho de que los derechos de los que se está hablando proceden del sistema normativo moral. No se está hablando de cualquier moral, sino de la moral ilustrada; la moral que prescinde de elementos y entes no humanos para su constitución y realización. El realce de lo estrictamente humano es precisamente lo que da a la concepción de los derechos humanos como derechos morales una acentuada ventaja frente al iusnaturalismo ${ }^{11}$.

\footnotetext{
9 VILLAVICENCIO, Luis (2010): "El constructivismo kantiano según Rawls como fundamento de los derechos humanos", en: Frónesis. Revista de Filosofía Jurídica, Social y Política (Volumen 17, № 1), p. 26.

10 La expresión derechos humanos como subespecie de los derechos morales corresponde a John Tasioulas. Véase TASIOULAS, John (2012): "On the Nature of Human Rights", en: coordinadores Gerhard Ernst y Jan-Christoph Heilinger, The Philosophy of Human Rights: Contemporary Controversies (Göttingen, De Gruyter), p. 19.

11 Para obtener una visión más amplia del concepto de derechos morales pueden verse, entre otros, Nino, Carlos (1990): "Sobre los derechos morales", en: Doxa (№ 7), pp. 311-325; Tugendhat, Ernst
} 
Lo dicho hasta ahora sobre la conexión derechos morales-derechos humanos requiere profundización, lo que se hará en la tercera sección. Pero antes de ello es conveniente ver cuáles son las objeciones que se han levantado contra esta concepción y que las mismas sean sopesadas. Ello permitirá tasar adecuadamente la pertinencia de la teoría de los derechos humanos como derechos morales.

\section{Habermas y la oposición a los derechos humanos como derechos morales}

Es conocida la ferviente oposición de Jeremy Bentham a los derechos morales $^{12}$, y en general al concepto de derechos no legales, aunque la crítica con mayor grado de elaboración conceptual y sistemática proviene de Jürgen Habermas, motivo por el cual las líneas siguientes se centrarán en las ideas de este último. Habermas estima que los derechos humanos deberían ser entendidos como derechos legales, lo que en el marco de sus ideas equivale a derechos fundamentales ${ }^{13}$. Para él, los derechos morales serían derechos que esperan a entrar en vigor, derechos que en realidad no son derechos ${ }^{14}$. Este punto de vista se basa sobre dos tipos de argumentos que actúan de forma concomitante. El primer argumento es de tipo pragmático: Habermas diferencia los sistemas normativos de la moral y del derecho, de tal manera que todo derecho subjetivo queda circunscrito en la esfera del derecho, es decir, los derechos son sólo derechos legales ${ }^{15}$. La finalidad de esta diferenciación yace en que Habermas quiere dar fundamento teórico a un sistema que regule de manera efectiva el comportamiento de los seres humanos, algo que no puede conseguir la moral. La moral solamente implica conocimiento u orientación para actuar, pero no determina la materialización de la acción ${ }^{16}$. Por el contrario, el derecho es a la

(1993): Vorlesungen über Ethik (Frankfurt del Meno, Suhrkamp), pp. 336-363; PARCERO, Juan (2001): "Derechos morales: concepto y relevancia", en: Isonomía (No 15), pp. 55-79 y StEINER, Hillel (2006): "Moral Rights", en: coordinador David Copp, The Oxford Handbook of Ethical Theory (New York, Oxford University Press), pp. 459-477.

12 Véase Bentham, Jeremy (1987 [1795]): "Anarchical Fallacies; Being an examination of the Declaration of Rights Issued during the French Revolution", en: editor Jeremy Waldron, Nonsense upon Stilts. Bentham, Burke and Marx on the Rights of Man (New York, Metuen), pp. 46-76.

13 Habermas, Jürgen (1996): Faktizität und Geltung. Beiträge zur Diskurstheorie des Rechts und des demokratischen Rechtsstaats (Frankfurt del Meno, Suhrkamp), p. 138.

14 Habermas, Jürgen (1996): Faktizität und Geltung. Beiträge zur Diskurstheorie des Rechts und des demokratischen Rechtsstaats (Frankfurt del Meno, Suhrkamp), p. 161.

15 Habermas, Jürgen (1996): Faktizität und Geltung. Beiträge zur Diskurstheorie des Rechts und des demokratischen Rechtsstaats (Frankfurt del Meno, Suhrkamp), p. 106.

16 Habermas, Jürgen (1996): Faktizität und Geltung. Beiträge zur Diskurstheorie des Rechts und des demokratischen Rechtsstaats (Frankfurt del Meno, Suhrkamp), pp. 137, 145-146. 
vez sistema de conocimiento u orientación y determina hacia la acción ${ }^{17}$. En resumidas cuentas, la moral en sí misma no tiene una fuerza de motivación que sea suficiente para conducirnos a materializar ciertas conductas, pues carece del elemento sanción o de poder de coacción, algo que es inherente al derecho ${ }^{18}$. En este sentido, el razonamiento de Habermas sería: si los derechos humanos son derechos morales, su realización estaría en peligro. Para evitar esto deben ser concebidos como derechos legales.

El segundo argumento es de orden programático o sistemático. Habermas se interesa por un sistema normativo que se refiera a la autonomía política y regule lo social, y no por uno que aluda exclusivamente a la autonomía de la voluntad particular y que consecuencialmente regule sólo lo individual. La voluntad individual está en el campo de lo moral, y aquí la pregunta rectora es ¿qué debo hacer? Por su parte, la autonomía política o colectiva se ubica en el campo del derecho, donde la pregunta capital es iqué debemos hacer? ${ }^{19}$ En cuanto al hecho de no considerar los derechos humanos como derechos morales, el razonamiento puede presentarse así: si la moral únicamente atiende a lo individual, y si se quiere que los derechos humanos regulen lo social, entonces éstos no deben ser vistos como derechos morales, sino como derechos legales, por cuanto es lo jurídico lo que atañe a lo social, mas no lo moral.

El planteamiento de Habermas, a pesar de lo refinado de su elaboración, no está exento de objeciones. En este orden de ideas, es casi evidente y debe admitirse que ciertamente hay diferencias entre el sistema normativo de la moral y del derecho, pero un primer equívoco está en que Habermas sostiene una visión excesivamente limitada de la moral, creando la impresión de afirmar implícitamente que no existen sanciones dentro de la misma. Tal pensamiento es errado, puesto que en la moral existe un sistema de sanciones que se manifiesta esencialmente en forma de sentimientos: indignación, molestia, vergüenza, etc. ${ }^{20}$. Siendo ello así, entonces se ve claramente que la moral no es tan débil o insuficiente -como Habermas piensa- para motivar a las personas hacia la acción. Aunado a lo dicho, resulta que en muchos casos se actúa de la manera debida no porque exista la amenaza de la sanción, sea moral o sea jurídica,

17 Habermas, Jürgen (1996): Faktizität und Geltung. Beiträge zur Diskurstheorie des Rechts und des demokratischen Rechtsstaats (Frankfurt del Meno, Suhrkamp), p. 146.

18 Habermas, Jürgen (1996): Faktizität und Geltung. Beiträge zur Diskurstheorie des Rechts und des demokratischen Rechtsstaats (Frankfurt del Meno, Suhrkamp), pp. 143, 148.

19 HaBERMAS, Jürgen (1996): Faktizität und Geltung. Beiträge zur Diskurstheorie des Rechts und des demokratischen Rechtsstaats (Frankfurt del Meno, Suhrkamp), pp. 190, 194 ss.

${ }^{20}$ Véanse Strawson, Peter (1974): "Freedom and Resentment", en: coordinador Peter Strawson, Freedom and Resentment and Other Essays (London, Methuen \& Co. Ltd), p.15 y TugendHat, Ernst (1993): Vorlesungen über Ethik (Frankfurt del Meno, Suhrkamp), pp. 20-21, 57-64. 
sino por el hecho de que ese correcto actuar se ha internalizado como algo moralmente correcto, o sea, por el hecho de que se está profundamente convencido de que actuar así es correcto. La internalización de las normas morales, al igual como puede suceder con las normas jurídicas, puede ser también una fuente de motivación para la acción. Las dos objeciones indicadas hablan en contra de la opinión de Habermas de que la moral no posee suficiente poder de motivación, al mismo tiempo que muestra que los derechos morales no son derechos que simplemente esperan ser juridificados: los derechos morales son derechos verdaderos y cuentan con un sistema de sanciones, al tiempo que adicionalmente disponen a los individuos para que actúen.

En cuanto al segundo tipo de argumentos expuesto por Habermas, no hay que poner en duda que en la moral existe un campo algo más amplio en favor de la autonomía individual de lo que pueda existir en el derecho, mas de allí no se desprende que la moral pueda ser considerada como un campo exclusivo de lo individual. Las reflexiones, decisiones y acciones morales se encuentran ineludiblemente conectadas con la vida social y colectiva, en virtud de que la moral es, ante todo, un constructo social. La moral y los derechos morales representan algo más que la voluntad individual, y no podrían existir si la vida social no jugara ningún papel. A través de los derechos morales no se busca solamente el bienestar individual, sino también el de la sociedad, el del grupo, el del colectivo. Es curioso que Habermas le asigne exclusivamente a la moral -y con ello indirectamente a los derechos morales- una función individual, mientras que no observa que en el campo del derecho lo individual también es muy importante. El sistema jurídico institucional no sólo se guía por la pregunta ¿qué debemos hacer?, sino también por la pregunta ¿qué debo hacer? De la misma manera, la moral responde a las preguntas ¿qué debo hacer? y ¿qué debemos hacer? Los derechos morales también tienen un sentido social, por cuanto pertenecen al sistema normativo social de la moral. Tomando en cuenta lo expuesto, oponerse a la idea de los derechos humanos como derechos morales, basándose en el carácter exclusivamente individual de la moral, no es procedente, ya que la moral no atiende exclusivamente a lo individual.

Visto está que los argumentos de Habermas en contra de la concepción de los derechos humanos como derechos morales no son convincentes. Siendo así, corresponde ahora centrarse propiamente en el núcleo de este escrito: las diferentes maneras de concebir los derechos humanos desde la perspectiva de los derechos morales.

\section{Derechos humanos en tanto derechos morales: el enfoque modesto y el riguroso}

Lo que se debe entender por derechos humanos en tanto derechos morales no es algo que esté libre de discusión. Por el contrario, existen diferentes posi- 
ciones que se refieren a la temática y, como consecuencia, conciben de diferente manera los derechos humanos. Dos son las propuestas más representativas, y que aquí se denominarán concepción modesta y concepción rigurosa. La compresión cabal de cada una de éstas requiere tener meridianamente claro cuál es su concepto de derechos morales y sus efectos sobre el concepto de derechos humanos. Por ello, en las subsecciones que forman esta segunda parte, primero se expondrá el concepto de derechos morales, luego se verá cómo influye éste sobre la noción de derechos humanos y, finalmente, se presentará un balance crítico. Así se procederá con las dos propuestas.

\subsection{La concepción modesta}

La denominada concepción modesta es sostenida principalmente por Joel Feinberg ${ }^{21}$, quien presenta la idea esencial de lo que son los derechos morales de la siguiente manera:

el término derechos morales puede ser aplicado a todos los derechos de los que se afirma que existen previa e independientemente de las reglas legales o institucionales. Los derechos morales, así concebidos, forman un género que es divisible en varias especies de derechos, teniendo éstos poco en común, salvo que no son -necesariamente- legales o institucionales ${ }^{22}$.

Una primera aproximación muestra que los derechos morales no son dependientes de las normas del derecho positivo. No obstante, se obtiene una idea más clara cuando se valora la clasificación de Feinberg de los derechos en general. Según él, hay tres tipos de derechos: derechos jurídicos, derechos morales convencionales y derechos morales verdaderos o reales. Los derechos legales son concedidos por el sistema del derecho positivo (leyes, decretos, etc.) y los derechos morales convencionales son concedidos por medio de las normas de la moral convencional de la comunidad, o sea, por las instituciones morales existentes en determinado momento. Por el contrario, los derechos

\footnotetext{
${ }^{21}$ Entre otros partidarios de la aquí llamada concepción modesta, pueden verse JONES, Peter (2013): "Moral Rights, Human Rights and Social Recognition", en: Political Studies (Volumen 61), pp. 267-281; Pogge, Thomas (2011): Weltarmut und Menschenrechte (Berlin/New York, De Gruyter), p. 62 y TASIOULAS, John (2012): "On the Nature of Human Rights", en: coordinadores Gerhard Ernst y Jan-Christoph Heilinger, The Philosophy of Human Rights: Contemporary Controversies (Göttingen, De Gruyter), pp. 17-59. La presente sección se centra sobre todo en las ideas de Joel Feinberg, por cuanto que es éste quien ha presentado la propuesta con mayor grado de elaboración conceptual. De cualquier manera, en adelante se hará mención a los autores antes indicados, cuando ello sea pertinente.

${ }^{22}$ FeInBerG, Joel (1973): "Human Rights", en: coordinador Joel Feinberg, Social Philosophy (New Jersey, Prentice-Hall), p. 84 (traducción propia). Una formulación similar del propio Feinberg es: "A man has a moral right when he has a claim the recognition of which is called -not (necessarily) by legal rules-but by moral principles, or the principles of an enlightened conscience" (FEINBERG, Joel (1970): "The Nature and Values of Rights", en: Journal of Value Inquiry (Volumen 4, № 4), p. 243).
} 
morales verdaderos no son otorgados por una moral convencional, pues ellos provienen de principios morales objetivos y universales, lo que significa que su existencia no requiere ni del sistema jurídico ni de las normas morales que rigen en una determinada sociedad ${ }^{23}$. A pesar de que los tres tipos de derechos no son de la misma índole, es posible, y de hecho sucede, que ellos se solapen, así que, por ejemplo, un derecho moral verdadero puede formar parte de la moral convencional y del sistema jurídico ${ }^{24}$. De lo dicho es importante destacar lo siguiente: primero, el criterio diferenciador entre derechos legales y morales es la fuente de donde emanan. Con otras palabras, los derechos jurídicos y los morales son diferentes porque emanan o tienen su origen en diferentes fuentes. Segundo, de allí resulta una importante característica de los derechos morales: la juridificación de los derechos morales no es una idea constitutiva de éstos. Se puede tener el deseo o el interés en que determinado derecho moral pase a formar parte del sistema jurídico positivo, pero su juridificación no es relevante para que haya un derecho mora ${ }^{25}$.

Con respecto a la diferencia entre los derechos morales verdaderos y los convencionales, expresa Feinberg que los verdaderos tienen su origen en principios objetivos y universales, y los convencionales derivan de cierta práctica social. Detrás de esta diferenciación se encuentra realmente la idea de que los derechos morales convencionales son derechos reconocidos, mas no así los verdaderos ${ }^{26}$. De esta forma, es el reconocimiento social lo que en última instancia realmente permite diferenciar entre derechos morales verdaderos y los convencionales. Viendo el contexto de lo planteado, resultan dos consecuencias significativas: primero, los derechos morales verdaderos pueden ser usados como patrón de crítica de los derechos convencionales; segundo, derechos morales en sentido

\footnotetext{
${ }^{23}$ Véase FeinberG, Joel (1990): "In Defense of Moral Rights: Their Bare Existence", en: coordinador Joel Feinberg, Freedom and Fulfillment. Philosophical Essays (Oxford, Princeton University Press), pp. 200-203.

${ }^{24}$ FeinBerG, Joel (1990): "In Defense of Moral Rights: Their Bare Existence", en: coordinador Joel Feinberg, Freedom and Fulfillment. Philosophical Essays (Oxford, Princeton University Press), pp. 200-201.

25 FeinBerG, Joel (1990): "In Defense of Moral Rights: Their Bare Existence", en: coordinador Joel Feinberg, Freedom and Fulfillment. Philosophical Essays (Oxford, Princeton University Press), p. 205.

${ }^{26}$ Feinberg parece ser de la opinión de que la moral convencional varía de grupo en grupo, por lo que ello no otorga un concepto suficientemente estable de lo que es un derecho moral en sentido estricto. Que la moral convencional es variable en el espacio y en el tiempo, da lugar a que se afirme que la moral del nazismo es una moral convencional válida (véase FeinBerG, Joel (1990): "In Defense of Moral Rights: Their Bare Existence", en: coordinador Joel Feinberg, Freedom and Fulfillment. Philosophical Essays (Oxford, Princeton University Press), p. 200). Sin embargo, la moral convencional y los derechos morales convencionales pueden ser criticados, en caso de que violen principios morales objetivos y universales (véase FeInBERG, Joel (1990): "In Defense of Moral Rights: Their Social Importan$\mathrm{ce}^{\prime \prime}$, en: coordinador Joel Feinberg, Freedom and Fulfillment. Philosophical Essays (Oxford, Princeton University Press), pp. 223-224).
} 
estricto son únicamente los Ilamados derechos morales verdaderos, en razón de que provienen de principios morales objetivos y universales. Ahora se nota más nítidamente que un entendimiento adecuado del concepto de derechos morales requiere la idea de lo prejurídico, además de la idea de fuente, de aquello de donde proviene el derecho en cuestión.

Si los derechos morales convencionales no son derechos morales en sentido estricto, surge la siguiente pregunta: ¿por qué los derechos morales convencionales son catalogados como derechos morales? En un primer momento puede decirse que la moral convencional es entendida como moral válida por Feinberg, por lo que los derechos que emanen de ella son entendidos igualmente como derechos morales. Ello es una interpretación plausible, aunque la verdadera razón parece ser otra y tiene visos pragmáticos. Como se dijo, según Feinberg, los derechos morales convencionales y los verdaderos pueden superponerse, lo que parece ser posible solamente cuando la moral convencional o la comunidad moral correspondiente acogen o reconocen los derechos morales verdaderos. Que los derechos morales sean reconocidos por la comunidad moral tiene una considerable ventaja en relación con los que no lo son: los derechos reconocidos pueden ser aplicados con mayor facilidad, puesto que gozan de un mayor grado de aceptación y respeto dentro de la sociedad. Feinberg es consciente de ello y no quiere dejar por fuera la posibilidad de que los derechos morales verdaderos disfruten de este beneficio, dado el caso de que entren a formar parte de la moral convencional. Esto no sería posible, si se afirmara que los únicos derechos morales son los derechos morales verdaderos.

\section{2. La noción de derechos humanos de la posición modesta}

La manera de entender los derechos morales que propone la concepción modesta tiene consecuencias de peso sobre el concepto de derechos humanos, y ciertamente Feinberg manifiesta que los derechos humanos son derechos morales ${ }^{27}$. Ello supone que para esta posición los derechos humanos tienen una naturaleza prejurídica, que es esencialmente moral. Evidentemente, aquí es aplicable una vez más el criterio del origen o fuente del respectivo derecho, lo que conduciría a expresar que, a diferencia de los derechos jurídicos, los derechos humanos encuentran su fuente en la moral. Ahora bien, en tanto que se trata de derechos morales, y siendo consecuentes con el planteamiento conceptual arriba expuesto, resulta que los derechos humanos son válidos y existen, aunque el sistema jurídico positivo no los reconozca. Aún más, también se infiere de allí que la idea de una necesaria juridificación queda excluida del

27 FeInBerG, Joel (1973): "Human Rights", en: coordinador Joel Feinberg, Social Philosophy (New Jersey, Prentice-Hall), p. 202. 
concepto de derechos humanos. Los derechos humanos, en tanto derechos morales, pueden coincidir materialmente con los derechos jurídicos, aunque no existen ni el deber moral ni la necesidad conceptual de que sean derechos legales. Este elemento conceptual que excluye la necesaria juridificación de los derechos humanos ha de ser tenido muy en cuenta, por cuanto es aquí donde fundamentalmente va a radicar la disparidad presente entre la posición modesta y la rigurosa. La concepción modesta es calificada como tal justamente porque es modesta en cuanto a la exigencia de que los derechos humanos sean convertidos en derechos legales.

A decir de Feinberg, los derechos humanos no son por su naturaleza derechos jurídicos, aunque tampoco son derechos morales convencionales, sino derechos morales verdaderos ${ }^{28}$. Esto es así porque los derechos humanos son derechos que poseen todos los seres humanos ${ }^{29}$. Dicho de otra manera, los derechos humanos son derechos morales verdaderos porque son universales; si los derechos humanos fuesen derechos morales no universales, entonces serían derechos morales convencionales, los cuales tienen una validez que se limita a la comunidad moral respectiva que posee su propio sistema moral. En este sentido, los derechos humanos, en tanto derechos morales verdaderos, también se basan y provienen de principios morales objetivos y universales. Entonces, así como los derechos humanos concebidos como derechos morales

\footnotetext{
${ }^{28}$ FeinberG, Joel (1973): "Human Rights", en: coordinador Joel Feinberg, Social Philosophy (New Jersey, Prentice-Hall), p. 85. En el texto del presente escrito se alude a la clasificación que hace Feinberg sobre los derechos morales en su obra In Defense of Moral Rights: Their Bare Existence del año 1990. Sin embargo, en un ensayo anterior del año 1973, titulado Human Rights, introdujo una clasificación diferente o -según sus propias palabras- "diferentes significados" de derechos morales. Según esta clasificación, los derechos morales son: a) derechos convencionales, que tienen su origen en las costumbres establecidas, independiente de si las leyes jurídicas reconocen estos derechos o no; b) derecho ideal, el cual no es necesariamente un derecho real, sino algo que debería ser un derecho positivo, ya sea legal o convencional; c) derechos de conciencia, que son exigencias cuyo reconocimiento y validez se pretenden, pero no necesariamente de acuerdo con reglas ideales, reales o convenciones, sino en conformidad con una conciencia moral ilustrada y d) exercise right, que no es propiamente un derecho, sino más bien una justificación moral para el ejercicio de los demás derechos. Según Feinberg, los derechos humanos son entendidos a veces como derechos ideales, a veces como derechos de conciencia y otras muchas como ambos (véase FEINBERG, Joel (1973): "Human Rights", en: coordinador Joel Feinberg, Social Philosophy (New Jersey, Prentice-Hall), pp. 84-85). Se puede ver fácilmente que la posición de Feinberg con respecto a los derechos humanos y los derechos morales se modificó en el transcurso del tiempo. En su obra del año 1990, arriba citada, ve los derechos humanos como derechos morales verdaderos, lo que en su clasificación del año 1973 se corresponde en cierta medida con los derechos de conciencia. Si se quiere ser algo más minucioso, es pertinente decir que el derecho moral ideal en general, y en tanto derecho humano en específico, es rechazado implícitamente en su última clasificación (año 1990), cuando se dice que la idea de que los derechos morales deben ser juridificados no es constitutiva del concepto de derechos morales.
}

29 FeinberG, Joel (1973): "Human Rights", en: coordinador Joel Feinberg, Social Philosophy (New Jersey, Prentice-Hall), p. 85. 
se distinguen de los derechos jurídicos en cuanto a su fuente, de igual forma los derechos humanos en tanto derechos morales verdaderos deberían diferenciarse -dentro del marco conceptual de esta propuesta- de los derechos morales convencionales en relación con su fuente: los convencionales encuentran su génesis en la moral positiva propia de una determinada comunidad moral, pero los derechos humanos, como ya se dijo, descansan sobre principios morales objetivos y universales y, por tanto, no son un constructo social ${ }^{30}$. Además de lo dicho, cabe mencionar dos cosas: primero, siendo los derechos humanos derechos morales verdaderos, no se requiere ningún reconocimiento social o ningún reconocimiento por parte de algún grupo social para que sean válidos $^{31}$. El reconocimiento social puede darse en la práctica, pero no se trata de un elemento conceptual constitutivo de los derechos humanos. Segundo, un punto diferenciador entre los derechos humanos y otros derechos morales que lesionen los derechos humanos sería el que éstos son verdaderos derechos morales, mientras que los otros no.

En conexión con Gregory Vlastos, Feinberg asevera que los derechos humanos presuponen que todas las personas tienen los mismos derechos y el mismo valor, lo que significa tanto como presentar el principio moral de la igualdad de todos los seres humanos como fundamento de dichos derechos ${ }^{32}$. La posesión igualitaria de los derechos humanos se justifica en el hecho de que todos los seres humanos tenemos la capacidad de situarnos en la posición del otro, lo que nos permite -esta pareciera ser la reflexión de Feinberg-darnos cuenta de qué es común a todos y qué no, y nos llevaría a la conclusión que los derechos humanos deben ser poseídos por todos ${ }^{33}$.

Peter Jones es partidario de un criterio similar al de Feinberg. De acuerdo con Jones, los derechos morales son derechos única y exclusivamente debido a su carácter moral ${ }^{34}$. El reconocimiento de los derechos morales por parte de la sociedad, a través de normas morales, leyes, derechos legales, etc., no es

\footnotetext{
30 TASIOULAS, John (2012): "On the Nature of Human Rights", en: coordinadores Gerhard Ernst y Jan-Christoph Heilinger, The Philosophy of Human Rights: Contemporary Controversies (Göttingen, De Gruyter), p. 26.

31 TaSiOulas, John (2012): "On the Nature of Human Rights", en: coordinadores Gerhard Ernst y Jan-Christoph Heilinger, The Philosophy of Human Rights: Contemporary Controversies (Göttingen, De Gruyter), p. 36.

32 FeinberG, Joel (1973): "Human Rights", en: coordinador Joel Feinberg, Social Philosophy (New Jersey, Prentice-Hall), p. 89.

33 FeinberG, Joel (1973): "Human Rights", en: coordinador Joel Feinberg, Social Philosophy (New Jersey, Prentice-Hall), pp. 93-94.

34 JONES, Peter (2013): "Moral Rights, Human Rights and Social Recognition", en: Political Studies (Volumen 61), p. 277.
} 
un componente elemental del concepto de derechos morales. Lo dicho es un paso conceptual necesario para poder afirmar que los derechos humanos tienen validez universal e independiente del sistema jurídico, en la medida en que estos derechos son vistos como derechos morales. Ello implica también que si los derechos humanos son derechos morales, su existencia no está sujeta al reconocimiento social, pues en este último caso no serían derechos universales. En este contexto teórico, si se tuvieran derechos humanos con motivo del reconocimiento social, uno sería portador de dichos derechos porque es miembro de cierto grupo social o comunidad política, pero no por el hecho mismo de ser humano ${ }^{35}$. Otro carácter conceptual de los derechos morales, introducido por Jones, es que la efectiva aplicación del derecho tampoco es un elemento constitutivo, ya que un derecho normalmente se concibe como algo diferente de su aplicación. Consecuencialmente, la idea de la necesaria aplicación de los derechos humanos tampoco es un componente conceptual de los mismos ${ }^{36}$.

\subsection{Balance crítico de la posición modesta}

La concepción modesta expuesta es muy atractiva, especialmente por la idea de que los seres humanos poseen derechos morales en general y derechos humanos en específico, sin que se requiera para ello el reconocimiento social. A esta concepción, sin embargo, se le pueden formular algunas consideraciones críticas. Una primera observación se refiere a la distinción entre derechos morales convencionales y verdaderos introducida por Feinberg. Según esa distinción, hay tan sólo una categoría de derechos morales en sentido estricto, y ellos serían los derechos morales que no requieren ni exigen ningún tipo de reconocimiento social para existir, es decir, los derechos morales verdaderos. Ello evidentemente impulsa a plantearse la pregunta acerca de si efectivamente lo convencional, lo creado por los seres humanos de forma voluntaria y colectiva no es verdadero. La tendencia de la ontología social de corte constructivista, liderada especialmente por John Searle, diría, con sobradas razones, que no es así. Los seres humanos estamos en capacidad de crear realidades, cosas verdaderas, y entre ellas pueden ser incluidos los derechos, sean morales o legales ${ }^{37}$. Así, los denominados derechos morales convencionales no tienen por qué oponerse

\footnotetext{
35 JONEs, Peter (2013): "Moral Rights, Human Rights and Social Recognition", en: Political Studies (Volumen 61), pp. 268, 274.

${ }^{36}$ Véase JOnes, Peter (2013): "Moral Rights, Human Rights and Social Recognition", en: Political Studies (Volumen 61), pp. 271-272.

${ }^{37}$ Véanse Searle, John (1995): The Construction of Social Reality (New York, The Free Press) y Searle, John (2006): "Social Ontology. Some Basic Principles", en: Anthropological Theory (Volumen 6, № 1), pp. 12-29.
} 
a los Ilamados derechos morales verdaderos; ambos son verdaderos derechos. Sin duda alguna se puede manifestar que existen derechos criticables, y eso es lo que pretende hacer Feinberg mediante su clasificación entre derechos morales convencionales y verdaderos, pero afirmar que unos son verdaderos y otros no conllevan una ruptura conceptual difícilmente sostenible, pues se está asimilando crítica con verdad. La clasificación mencionada asume que existen ciertos patrones objetivos que nos facultan para determinar la verdad o falsedad contenida en los derechos morales, y esos patrones son los principios morales objetivos. En este caso, objetividad da a entender que se trata de algo que posee una existencia no subordinada a la voluntad de los individuos. Pero ¿realmente existen los principios morales en sí mismos como algo autónomo? ¿Acaso no es la moral un producto social? La clasificación de Feinberg luce, pues, conceptualmente inadecuada, por cuanto desemboca en la anulación de lo social, lo que es inadmisible, por la sencilla razón que lo social es ínsito al sistema normativo moral.

La observación recién planteada incide sobre el concepto de derechos humanos. A este tenor, los derechos humanos ya no pueden oponerse a otros derechos que pueden implicar la lesión de los derechos humanos, en tanto que éstos son verdaderos: ambos derechos son sencillamente verdaderos. Con esta crítica los derechos humanos dejan de ser vistos como algo estrictamente objetivo o como algo que tiene una existencia que no depende de la realidad social ni de los individuos. Esto se conecta con una segunda observación crítica que se le plantea a la concepción modesta, y que se refiere a la idea conforme con la cual los derechos humanos en tanto derechos morales no requieren el reconocimiento social para su existencia. Los derechos humanos, así como cualquier sistema normativo social, apuntan a regular relaciones sociales de cierto orden, especialmente las relaciones entre el Estado y los individuos que aluden a aspectos esenciales de la vida humana (educación, salud, seguridad, etc.). Estas relaciones tienen un contexto social e histórico específico y se hace necesario que los involucrados aporten argumentos pertinentes para justificar la existencia de los derechos, pues en última instancia se trata de la limitación de la capacidad de acción de un agente, que es básicamente el Estado. Que los derechos humanos hagan alusión al necesario reconocimiento social, no significa que de hecho el Estado deba aceptar esos derechos para ser sujeto pasivo u obligado. Únicamente significa que se deben aportar argumentos de suficiente peso que conviertan esos derechos en algo racional y razonablemente aceptable. Todo este proceso de justificación ubica la existencia de los derechos humanos en el ámbito del necesario reconocimiento social. El problema de la posición modesta yace justamente en que niega u obvia la trascendencia que tiene el reconocimiento social para la constitución de los derechos humanos. 
Como tercera observación, recuérdese que representantes de esta postura -especialmente Jones- sostienen que la efectiva aplicación del derecho y su conservación no son algo constitutivo del concepto de derechos morales en general, lo que significaría que la presión social, incluyendo la sanción, no es esencial para el concepto de derechos humanos y que su efectivo respeto no es algo significativo, ni desde la perspectiva conceptual ni desde el ángulo de la práctica. Siendo así, puede ser planteada la siguiente pregunta: ¿qué sentido tiene poseer un derecho cuya conservación y aplicación no son relevantes? Una respuesta adecuada a esta pregunta sería que un derecho del tipo propuesto por la posición modesta tendría un papel político-moral destacado, sólo en el caso de que se quieran criticar normas, instituciones, etc., a fin de posibilitar la modificación o, dado el caso, la extinción de las normas, instituciones, etc., en cuestión. Entendidos de esta manera, los derechos humanos en tanto derechos morales tienen básicamente un rol crítico ${ }^{38}$. Esta es una consecuencia lógica de la manera como Feinberg y Jones dilucidan los conceptos de derechos morales y derechos humanos.

La trascendencia de disponer de puntos de vistas morales y políticos que permitan juzgar y criticar la realidad socio-normativa es indiscutible, como sucede con los derechos humanos, según esta posición; mas de la mera circunstancia de que a los derechos humanos les corresponde fundamentalmente un rol crítico no se colige que ellos sean derechos en sentido estricto, por cuanto, a diferencia de lo que opina Jones, la representación conceptual de lo que es un derecho está unida necesariamente con la idea de la conservación y aplicación del mismo. Esto es así porque el concepto de derecho en general contiene la idea de que ciertamente se posee la justificación debida para alcanzar la protección de determinado interés, lo que es factible indudable y necesariamente por medio de las nociones de conservación y efectiva aplicación del derecho. Por tanto, el concepto de derechos humanos propuesto por la posición modesta no puede ser asociado con la idea de derechos en sentido estricto. Decir que conceptualmente la conservación y la efectiva aplicación de los derechos humanos no son constitutivas, aunque la existencia de los mismos se afirma y defiende, equivale a aseverar que los derechos humanos existen, a pesar de que el ejercicio de éstos no sea posible ni se deba garantizar. Ello es un desatino teórico y práctico, ya que el concepto de derechos humanos

\footnotetext{
${ }^{38}$ Feinberg acepta, en efecto, que los derechos morales deben cumplir con la función de servir como un punto de vista crítico y que esos derechos pertenecen a la esfera de la moral crítica. También manifiesta que con su posición invoca la moral crítica, a efectos de dar fundamento a exigencias verdaderas que no son necesariamente reconocidas por las normas de las instituciones sociales (FEINBERG, Joel (1990): "In Defense of Moral Rights: Their Bare Existence", en: coordinador Joel Feinberg, Freedom and Fulfillment. Philosophical Essays (Oxford, Princeton University Press), p. 201 y 219).
} 
ha de servir de base y estar conectado con la práctica normativa, con la regulación de ciertas relaciones sociales, con algo que obligatoriamente debe ocurrir. Sobre un criterio como éste, aunque no específicamente en relación con las opiniones de Feinberg y Jones, Henry Shue ha argüido acertadamente que pretender garantizar a las personas un derecho que de hecho no pueden ejercer es algo fraudulento, equivalente a conceder a las personas tickets para comer, sin que realmente les entreguen los alimentos que les corresponden en virtud de los tickets ${ }^{39}$.

Si se desea salvar algo significativo de esta concepción, la mejor vía sería aceptando la relevancia que tiene el criterio de que los derechos humanos sirven como puntos críticos de la realidad normativa. Pero las demás consecuencias que emanan de la posición modesta realmente no fortalecen, sino que debilitan la noción de derechos humanos.

\subsection{La concepción rigurosa}

La denominada posición rigurosa contiene supuestos conceptuales diferentes de los de la posición modesta, y se opone a ella en gran medida. Ernst Tugendhat ha centrado parte de su obra en defender esta posición. De acuerdo con él, los derechos humanos son parte de un orden estatal legítimo y la fuente de la legitimidad será siempre un concepto moral ${ }^{40}$. Es evidente, entonces, que Tugendhat aspira a sustentar una postura desde la cual el Estado en sí y su accionar puedan ser sometidos a juicio y/o legitimados. Partiendo de esta idea básica, afirma que los derechos humanos son derechos morales. Que un derecho sea un derecho moral significa que puede ser justificado desde el ángulo del respeto (Achtung) universal e igualitario ${ }^{41}$ o desde el ángulo de la consideración igualitaria de todos los intereses ${ }^{42}$. Un derecho se justifica moralmente cuando supera el test de la observación imparcial ${ }^{43}$, o sea, cuando el derecho se muestra como algo deseable desde una perspectiva imparcial ${ }^{44}$. Ahora, los derechos morales, y con ello los derechos humanos, no son derechos innatos, sino concedidos, al igual

\footnotetext{
${ }^{39}$ Véase Shue, Henry (1996): Basic Rights: Subsistence, Affluence, and U.S. Foreign Policy, segunda edición. (Princeton, Princeton University Press), p. 27.

40 Tugendhat, Ernst (1998): "Die Kontroverse um die Menschenrechte," en: coordinadores Stefan Gosepath y Georg Lohmann, Philosophie der Menschenrechte (Frankfurt del Meno, Suhrkamp), p. 48.

41 Tugendhat, Ernst (1993): Vorlesungen über Ethik (Frankfurt del Meno, Suhrkamp), p. 336.

42 Tugendhat, Ernst (1993): Vorlesungen über Ethik (Frankfurt del Meno, Suhrkamp), p. 49.

${ }^{43}$ Véanse Tugendhat, Ernst (1993): Vorlesungen über Ethik (Frankfurt del Meno, Suhrkamp), p. 351 y LoHMAnN, Georg (1998): "Menschenrechte zwischen Moral und Recht", en: coordinadores Stefan Gosepath y Georg Lohmann, Philosophie der Menschenrechte (Frankfurt del Meno, Suhrkamp), p. 68.

${ }^{44}$ Tugendhat, Ernst (1993): Vorlesungen über Ethik (Frankfurt del Meno, Suhrkamp), pp. 348-349.
} 
que cualquier otro derecho ${ }^{45}$. Característico de esta posición es aseverar que los derechos morales son concedidos por la comunidad moral o, mejor aún, por nosotros, siempre que nos entendamos como sujetos morales que pertenecen a la mentada comunidad ${ }^{46}$. Los derechos humanos en tanto derechos morales no se conceden a ciertos individuos, sino a todos los seres humanos, lo que significa aceptar que son derechos universales ${ }^{47}$. Algo diferente no se puede esperar en la concepción de Tugendhat, puesto que éste considera que la moral tiene una validez universal, como se dijo antes. Con otras palabras, si la moral es universal, entonces las normas que están contenidas en ella, y que a su vez dan origen a derechos -incluyendo los derechos humanos-, han de ser universales.

Los derechos morales no constituyen una categoría indiferenciada de derechos. Por el contrario, Tugendhat manifiesta que se debe diferenciar entre derechos morales fuertes y débiles. Los débiles serían los derechos cuyo respeto uno puede exigir (einfordern) de manera directa frente a la persona obligada, pero que no facultan para que se pueda recurrir a una tercera instancia ante la cual se pueda demandar (einklagen) su respeto, ya sea que esta tercera instancia sea el Estado o cualquier otra instancia de tipo social ${ }^{48}$. Los derechos morales fuertes, por su parte, son aquellos de los cuales emana el deber moral colectivo de constituir una instancia jurídica que nos represente a todos, y ante la cual se pueda demandar (einklagen) la satisfacción y el respeto del respectivo de-

45 Tugendhat, Ernst (1993): Vorlesungen über Ethik (Frankfurt del Meno, Suhrkamp), p. 346 y TugendHAT, Ernst (1998): "Die Kontroverse um die Menschenrechte," en: coordinadores Stefan Gosepath y Georg Lohmann, Philosophie der Menschenrechte (Frankfurt del Meno, Suhrkamp), p. 48. Markus Stepanians se ha opuesto firmemente a la idea de Tugendhat de que los derechos humanos son derechos concedidos. Según Stepanians, existe un componente de preferencias metafísicas que sitúa la fuente de los derechos humanos en propiedades innatas de sus titulares. Tales propiedades innatas son las necesidades fundamentales y los intereses humanos, que son resultado de una evolución tanto biológica como cultural, y apunta Stepanians que los principios que ordenan la satisfacción de las necesidades fundamentales son producto de una reflexión humana (STEPANiAns, Markus (2005): "Menschenrechte als moralische Rechte und als juridische Rechte", en: coordinadores Klaus Girardet y Ulrich Nortmann, Symposium, Menschenrechte und europäische Identität-die antiken Grundlagen (Stuttgart, Franz Steiner Verlag), pp. 2, 19). Se deben notar dos cosas: primero, Stepanians parece cometer una falacia naturalista, en tanto que afirma que la existencia de las necesidades fundamentales -naturales- sirven como fuente de algo normativo, o sea, de los derechos humanos. Para evitar esta falacia, afirma luego que los principios que establecen el deber de satisfacer las necesidades fundamentales tienen un origen racional, en la medida en que son producto de la reflexión humana. Si ello es así, y esto como segunda observación, entonces la posición de Stepanians está mucho más cerca de la de Tugendhat de lo que el propio Stepanians cree. La razón es que los derechos humanos ya no tienen como base cualidades innatas de tipo estrictamente natural, sino que son constructos que nacen con motivo de la reflexión humana.

46 Tugendhat, Ernst (1993): Vorlesungen über Ethik (Frankfurt del Meno, Suhrkamp), p. 346.

47 Tugendhat, Ernst (1998): "Die Kontroverse um die Menschenrechte," en: coordinadores Stefan Gosepath y Georg Lohmann, Philosophie der Menschenrechte (Frankfurt del Meno, Suhrkamp), p. 48.

${ }^{48}$ Tugendhat, Ernst (1993): Vorlesungen über Ethik (Frankfurt del Meno, Suhrkamp), p. 348. 
recho moral. Para expresarlo con mayor claridad, los derechos morales fuertes conllevan el deber moral de erigir el Estado y convertir estos mismos derechos en derechos legales ${ }^{49}$. La razón para su positivización, según Tugendhat, sería obtener la protección legal del respectivo derecho moral, por cuanto se trata de derechos que uno quiere que no sean discutidos por los demás, y al mismo tiempo también desea que sean protegidos a través del actuar de los demás ${ }^{50}$. A efectos conceptuales, aquí es importante mencionar dos cosas: primero, el punto diferenciador entre derechos morales débiles y fuertes no es la efectiva existencia o inexistencia de una tercera instancia, sino el hecho de que los derechos morales fuertes implican la posibilidad de exigir la constitución del Estado, con el objeto de lograr la protección de los mismos. Segundo, los derechos morales fuertes pueden ser caracterizados como derechos de dos niveles, ya que, en un primer nivel, cada derecho fuerte contiene una obligación que se dirige a determinada persona y, en un segundo nivel, implica la obligación de constituir una tercera instancia y legalizar tales derechos, que es una obligación cuyos destinatarios somos todos ${ }^{51}$.

A los ojos de Tugendhat, los derechos humanos son derechos morales que deben ser incluidos en el sistema legal. Se trata de derechos morales, por cuanto son concedidos por la moral o, mejor dicho, en base a argumentos morales $^{52}$, y se deben institucionalizar legalmente porque su efectivo respeto depende del actuar del Estado y porque su protección legal es deseable desde una perspectiva imparcial ${ }^{53}$, de donde se concluye que los derechos humanos son derechos morales fuertes. Con respecto a la visión de Tugendhat, es menester comprender que los derechos humanos son tales no porque deban ser positivizados legalmente o porque ya formen parte del aparato estatal, sino por el hecho de que ellos valen moralmente como derechos. Y es en este momento cuando emergen palmariamente los elementos conceptuales que separan a la posición modesta de la rigurosa. La posición rigurosa promueve y defiende que los derechos humanos no se tienen por el hecho de ser humano, sino que son derechos concedidos. Los derechos humanos se poseen porque los otros consideran que es racional y razonable -sobre bases morales- ser titular de derechos humanos. De igual forma, otro punto diferenciador es que la posición rigurosa sostiene que los derechos humanos son esencialmente morales, pero

\footnotetext{
49 Tugendhat, Ernst (1993): Vorlesungen über Ethik (Frankfurt del Meno, Suhrkamp), p. 350.

${ }^{50}$ Tugendhat, Ernst (1993): Vorlesungen über Ethik (Frankfurt del Meno, Suhrkamp), p. 350.

51 Véase WILDT, Andreas (1998): "Menschenrechte und moralische Rechte", en: coordinadores Stefan Gosepath y Georg Lohmann, Philosophie der Menschenrechte (Frankfurt del Meno, Suhrkamp), p. 130.

52 Tugendhat, Ernst (1993): Vorlesungen über Ethik (Frankfurt del Meno, Suhrkamp), pp. 350-363.

53 Tugendhat, Ernst (1993): Vorlesungen über Ethik (Frankfurt del Meno, Suhrkamp), p. 351.
} 
existe además la obligación moral de institucionalizarlos legalmente. Como se vio en la subsección 4.2., los aspectos conceptuales de mayor peso de la posición modesta son el que ni exige la positivización de los derechos humanos en tanto morales ni acepta que se trata de derechos concedidos.

Retomando la exposición, a los efectos de distinguir los derechos humanos en tanto derechos morales fuertes de otros derechos morales, que también pueden ser fuertes o débiles, Tugendhat recurre al concepto de necesidad, más específicamente, al concepto de necesidades fundamentales ${ }^{54}$. De tal manera que puede inferirse que los derechos humanos están conectados, de una u otra forma, con la satisfacción de necesidades fundamentales. Otro punto trascendental para Tugendhat es dejar claro que los derechos humanos tienen una doble manifestación en lo que se refiere al sujeto pasivo u obligado: los derechos humanos existen primariamente frente a los otros, en tanto individuos ${ }^{55}$, y secundariamente frente al Estado, en caso de que los individuos no respeten dichos derechos. Por lo tanto, el Estado tendría nada más que una función auxiliar y sería un obligado secundario ${ }^{56}$.

El filósofo Rex Martin es otro de los destacados representantes de la aquí Ilamada posición rigurosa. A decir de Martin, los derechos legales son derechos porque cumplen con tres requisitos: el reconocimiento de una pretensión en tanto derecho, el mantenimiento del derecho y la promoción del mismo ${ }^{57}$. Igual criterio se aplica también a los derechos humanos, de forma que ellos precisan de reconocimiento social, mantenimiento y promoción para poder ser asumidos como derechos $^{58}$, aunque lo especial de éstos es que son derechos morales, derechos no legales, lo que significa que las normas que constituyen o dan base a los derechos humanos son normas morales ${ }^{59}$. Los derechos humanos son, en consecuencia, derechos que se justifican por medio de argumentos morales. Pero Martin apunta que no es la simple existencia de argumentos morales lo que da lugar a los derechos humanos, sino el reconocimiento social de tales derechos ${ }^{60}$,

\footnotetext{
54 Tugendhat, Ernst (1993): Vorlesungen über Ethik (Frankfurt del Meno, Suhrkamp), p. 358.

${ }_{55}$ Una posible explicación de por qué Tugendhat asume que los derechos humanos regulan principalmente relaciones entre individuos es que él intenta oponerse a una concepción puramente liberal de estos derechos, concepción que tiene como foco exclusivo la relación de los particulares, en tanto portadores de derechos, con el Estado en su rol de sujeto obligado (véase TUGENDHAT, Ernst (1993): Vorlesungen über Ethik (Frankfurt del Meno, Suhrkamp), pp. 350-363).

56 Tugendhat, Ernst (1993): Vorlesungen über Ethik (Frankfurt del Meno, Suhrkamp), p. 351.

57 Martin, Rex (1997): A System of Rights (New York, Clarendon Press), capítulo 3.

${ }^{58}$ Martin, Rex (1997): A System of Rights (New York, Clarendon Press), pp. 77-83.

59 MARTIN, Rex (1997): A System of Rights (New York, Clarendon Press), p. 77.

60 Martin, Rex (2013): "Human Rights and the Social Recognition Thesis", en: Journal of Social Philosophy (Volumen 44, № 1), p. 10 y MARTIN, Rex (1997): A System of Rights (New York, Clarendon Press), p. 77.
} 
dejando casi de lado los otros dos requisitos arriba mencionados (mantenimiento del derecho y promoción del mismo). Para afinar un poco más la noción de reconocimiento social y entender mejor su repercusión sobre el concepto de derechos humanos como derechos morales, es necesario decir que, según Martin, uno está moralmente obligado únicamente si se está en la posición de reconocer el deber o, dicho de otra manera, cuando uno es consciente de ese deber, porque al fin y al cabo se trata de limitar la libertad de alguien ${ }^{61}$. Esto no significa que uno tiene el deber que uno quiere o desea tener, sino el deber que uno racional y razonablemente debería aceptar.

Pues bien, el reconocimiento social de los derechos humanos es una tarea que Martin asigna, expresa y principalmente -aunque no exclusivamente-, al Estado $^{62}$. Dicha postura se sostiene sobre dos argumentos. Conforme con el primer argumento, los derechos humanos son exigencias que se dirigen ante todo ${ }^{63}$ contra el Estado, lo que limita considerablemente su poder y su accionar, por lo que se hace necesario que el Estado reconozca estos derechos y los deberes contenidos en ellos ${ }^{64}$. Este argumento es, en gran medida, previsible, puesto que Martin, como ya se dijo, opina que el obligado debe estar en la posición moral de reconocer o aceptar la norma que lo obliga. El segundo argumento consiste en un recurso a la vida social: el discurso en torno a los derechos humanos parte de la premisa de que los seres humanos viven en sociedades organizadas y que los bienes que se pretenden alcanzar por medio de estos derechos solamente se obtienen en el marco de este tipo de sociedades. Por ello, las exigencias contenidas en los derechos humanos se dirigen ante todo a las sociedades organizadas, y éstas satisfacen dichas exigencias por medio de sus instituciones, de entre las cuales la más destacada es el Estado ${ }^{65}$. Que el reconocimiento social de los derechos humanos sea una tarea del Estado

\footnotetext{
${ }^{61}$ Martin, Rex (1997): A System of Rights (New York, Clarendon Press), p. 78 y MARTIN, Rex (2011): "Natural Rights, Human Rights and the Role of Social Recognition", en: Collingwood and British Idealism Studies (Tomo 17, № 1), pp. 97-98.

${ }^{62}$ Martin, Rex (1997): A System of Rights (New York, Clarendon Press), p. 97 y MARTIN, Rex (2013): "Human Rights and the Social Recognition Thesis", en: Journal of Social Philosophy (Volumen 44, $\left.\mathrm{N}^{\circ} 1\right)$, pp. 9-10, 17-18.

${ }^{63}$ Martin no niega que existan otras instituciones sociales que puedan ser vistas como obligadas. Ejemplo de ello son las empresas privadas que se dedican a actividades socialmente relevantes, como las empresas de salud. Martin destaca, no obstante, el papel del Estado, en tanto que es la institución social más significativa. Véase MARTIN, Rex (2013): "Human Rights and the Social Recognition Thesis", en: Journal of Social Philosophy (Volumen 44, No 1), p. 9.

${ }^{64}$ Martin, Rex (1997): A System of Rights (New York, Clarendon Press), p. 87.

${ }^{65}$ Martin, Rex (2013): "Human Rights and the Social Recognition Thesis", en: Journal of Social Philosophy (Volumen 44, №. 1), pp. 9-10 y MARTIN, Rex (1997): A System of Rights (New York, Clarendon Press), p. 87.
} 
conduce inevitablemente a afirmar que la realización de los mismos se logra fundamentalmente a través de su inclusión en el sistema jurídico positivo ${ }^{66}$. Ello quiere decir igualmente que los derechos humanos, a objeto de ser entendidos como derechos, deben juridificarse, porque sólo así reciben el reconocimiento social necesario que permite otorgarles el estatus de derechos.

A pesar de las diferencias con las ideas de Tugendhat, hay un hilo conductor que permite que Martin sea incluido en la posición rigurosa. Primero, se sostiene que los derechos humanos en tanto derechos morales son concedidos, o sea, no son derechos que se tienen como algo inherente y, segundo, se le da un puesto preponderante a la juridificación de los mismos. Estos dos aspectos, como se indicó, son característicos de la posición rigurosa ${ }^{67}$.

\subsection{Las insuficiencias de la posición rigurosa}

Con respecto a la posición modesta, la posición rigurosa presenta la ventaja de que acerca el concepto de derechos humanos un poco más a lo humano, lo que se consigue por medio de la tesis conforme con la cual los derechos humanos en tanto derechos morales son concedidos por nosotros, son un resultado del reconocimiento social. Somos los seres humanos, o la comunidad moral -para emplear palabras de Tugendhat-, la fuente de los derechos humanos. La concepción modesta, si se ve con cuidado, está impedida para dar una respuesta conceptual definitiva sobre esta materia. La tesis del reconocimiento social también trae otro punto a favor de la concepción rigurosa, porque el reconocimiento social ayuda a generar eficacia en cuanto al respeto y promoción de los derechos humanos: si son los seres humanos quienes reconocen ciertos derechos como necesarios y existentes, pues ello coopera en que su efectiva aplicación sea menos complicada. Admitido lo anterior, debe aceptarse que la posición rigurosa también contiene determinadas insuficiencias que la debilitan conceptualmente.

En este orden de ideas, y de la mano de Thomas Pogge, se puede decir que la tesis según la cual los derechos humanos en tanto derechos morales deberían ser juridificados es criticable. La razón es que la tesis en cuestión comprende una

\footnotetext{
${ }^{66}$ Martin, Rex (2013): "Human Rights and the Social Recognition Thesis", en: Journal of Social Philosophy (Volumen 44, № 1), p. 18.

${ }^{67}$ Robert Alexy y Alfonso Ruiz Miguel son partidarios de un enfoque similar al de Tugendhat y Martin, y sostienen que la juridificación de los derechos humanos es un rasgo conceptual de los mismos. Véanse Ruíz M., Alfonso (1990): "Los derechos humanos como derechos morales", en: Anuario de Derechos Humanos de la Universidad Complutense de Madrid ( $N^{\circ}$ 6), pp. 152, 155-156 y AlEXY, Robert, (1998): "Die Institutionalisierung der Menschenrechte im demokratischen Verfassungsstaat", en: coordinadores Stefan Gosepath y Georg Lohmann, Philosophie der Menschenrechte (Frankfurt del Meno, Suhrkamp), pp. 249-251, 254-264.
} 
exigencia que es, por una parte, demasiado fuerte $y$, por otra parte, demasiado débil. La exigencia es demasiado fuerte, pues los seres humanos pueden tener un acceso seguro a los bienes que tratan de garantizar los derechos humanos, sin necesidad de poseer derechos legales, lo que ocurre en el caso de los derechos morales. La exigencia, al mismo tiempo, es demasiado débil, debido a que los derechos jurídicos no siempre son suficientes para asegurar el acceso a los bienes que son objeto de los derechos humanos. Por ejemplo, muchísimos pobres no pueden hacer valer sus derechos legales, por el hecho de que carecen de los medios económicos para ello ${ }^{68}$. Esta opinión de Pogge deja claro que la juridificación de los derechos humanos no es adecuada para abarcar la idea de estos derechos en su totalidad, en virtud de que la juridificación deja por fuera varios aspectos que, desde la perspectiva de la moral, deben ser tomados en cuenta ${ }^{69}$.

En el marco de lo que se está comentando sobre los derechos humanos en tanto derechos legales, surge una observación puntual que está dirigida a la propuesta de Martin. Para éste, como se expuso, los derechos humanos son derechos morales, pero adquieren su verdadero carácter de derecho cuando son reconocidos por el Estado. El asunto está en que si los derechos humanos se conceptualizan de esa manera, entonces resulta que al final realmente se trataría de derechos legales, mas no de derechos prejurídicos, que es precisamente el aporte esencial que la teoría de los derechos morales trae consigo. Visto así, resulta que dentro del planteamiento de Martin yace una contradicción obvia que indiscutiblemente afecta toda su construcción conceptual: los derechos humanos en tanto derechos morales hacen depender su existencia de lo jurídicopositivo. Si esto fuese así, entonces los derechos humanos no serían derechos morales. Al fin y al cabo, parece que para Martin lo verdaderamente significativo es el carácter legal de los derechos humanos, puesto que ello es lo que hace posible la efectiva aplicación de los mismos. Siendo ello así, entonces aparece una observación adicional: una visión estrictamente jurídica de los derechos humanos vulnera el carácter universal de éstos. En el ámbito de esta propuesta, los derechos humanos sencillamente no pueden ser universales, por el hecho de que su existencia y validez están limitadas al espacio dentro del cual cada Estado ejerce su poder soberano.

\footnotetext{
68 Pogge, Thomas (2011): Weltarmut und Menschenrechte (Berlin/New York, De Gruyter), pp. 62-63.

69 Por derechos humanos entiende Pogge las exigencias morales dirigidas a ciertas instituciones sociales coactivas, las cuales deben estar conformadas de tal manera que garanticen a los interesados el acceso a determinado bien (véase PogGe, Thomas (2011): Weltarmut und Menschenrechte (Berlin/New York, De Gruyter), p. 63). Dicha compresión institucional, como Pogge la llama, no conlleva la conexión conceptual entre los derechos humanos en tanto derechos morales y la obligación de convertirlos en derechos legales, aunque tampoco excluye que ello sea posible y conveniente (véase PogGE, Thomas (2011): Weltarmut und Menschenrechte (Berlin/New York, De Gruyter), pp. 61-63).
} 
Un segundo grupo de observaciones tiene como objeto el papel que los partidarios de la posición rigurosa le atribuyen al Estado. De esta suerte, manifestar, como lo hace Tugendhat, que la existencia del Estado se hace necesaria o se legitima porque hay ciertos derechos morales que deben ser juridificados y aplicados causa, cuando menos, cierta perplejidad. Desde la visión de Tugendhat, esta manera de legitimar el Estado tiene -en principio- sentido, por cuanto él parte de la hipótesis de que los derechos humanos aluden primordialmente a las relaciones entre los individuos y que el Estado tiene la función de cooperar en la regulación de estas relaciones. Por ello, el Estado funcionaría como la tercera instancia imparcial que ha de decidir sobre los conflictos en materia de derechos humanos que se presentan entre los individuos. Un vistazo a la realidad pone al descubierto, no obstante, que la principal amenaza, así como el principal violador de los derechos humanos, es el Estado. La historia de estos derechos está marcada por la constante confrontación existente entre el Estado y los intereses de los individuos y otras manifestaciones de la vida humana, como son los colectivos (étnicos, religiosos, etc.). Los derechos humanos son instrumentos de defensa que se oponen principalmente al poder del Estado, y no a las acciones de los individuos. Los derechos humanos son triunfos frente al Estado, triunfos que colocan límites a su margen de acción ${ }^{70}$. La conciencia de nuestra realidad es, pues, un argumento de peso contra la intención de Tugendhat de legitimar el Estado a través de los derechos humanos y de otorgarle fundamentalmente un papel de árbitro, antes que darle el rol básico que debe cumplir: primer obligado o primer sujeto pasivo. La inclusión del Estado como elemento conceptual de los derechos humanos en tanto derechos morales se justifica, siempre que sea a título de principal obligado. Naturalmente, con ello no se pretende decir que los individuos u otros entes no puedan ni deben ser vistos conceptualmente como portadores de deberes, nada más se intenta recalcar -nuevamente-que el principal obligado es el Estado.

La posición rigurosa, representada en Tugendhat y Martin, muestra una tendencia bastante marcada a exponer al Estado como la única instancia encargada de la aplicación de los derechos humanos. Esto es contraproducente para la noción de los derechos humanos en tanto derechos morales y la debilita considerablemente, en virtud que se está restando importancia, menospreciando u olvidando que la moral dispone de un sistema de sanción que hace posible lograr el respeto de los derechos en cuestión. De este modo, buscando darle conceptualmente una mayor posibilidad de realización a los derechos humanos mediante el recurso casi exclusivo al Estado, Martin y Tugendhat no le hacen un gran favor a la teoría de los derechos humanos en tanto derechos morales; por el contrario, la perjudican.

${ }_{70}$ Dworkin, Ronald (1977): Taking Rights Seriously (London, Duckworth), p. 153. 
Para culminar esta sección, y con el propósito de evitar confusiones, es pertinente explicar que las críticas formuladas en este escrito a la manera como la posición rigurosa concibe la juridificación de los derechos humanos y el papel que tiene el Estado no significan una oposición absoluta ni a la juridificación de estos derechos ni a la relevancia conceptual del Estado. La crítica recae precisamente sobre la excesiva importancia que se le da tanto al poder estatal como a la juridificación, lo que conduce a conclusiones conceptuales bastante curiosas, especialmente en el caso de Martin.

\section{Sobre una adecuada noción de los derechos humanos en tanto derechos morales}

Las dos posiciones arriba expuestas se corresponden con diferentes teorías sobre los derechos humanos en tanto derechos morales, y ciertamente se deben tomar en cuenta las diferencias existentes entre ellas. Aspecto significativo a resaltar es, no obstante, que ambas posiciones asumen la moral como un componente irrenunciable para la constitución del concepto de los derechos humanos. Soy del criterio de que una adecuada formulación de este concepto no tiene necesariamente que adherirse de forma incondicional a alguna de las posiciones antes tratadas, precisamente debido a las insuficiencias por las que cada una de ellas se encuentra minada, aunque por supuesto es un acto de honestidad reconocer sus fortalezas y darles cabida al momento de plantear una noción filosófica de los derechos humanos. Las debilidades y fortalezas de una concepción dependen de la construcción conceptual en sí (por ejemplo, sus contradicciones internas), así como también en gran parte de la representación propia que se tiene de los derechos humanos. Tal representación no debería ser algo arbitrario o el resultado de nuestra simple facultad de querer algo, sino más bien el resultado de un proceso de reflexión que, a fin de cuentas, tenga como meta la defensa y promoción de los asuntos más esenciales de la vida humana.

Una adecuada comprensión de los derechos humanos como derechos morales implica asumir el importante papel crítico que les corresponde, en tanto que sirven como principal punto de vista o piedra de toque con la cual las instituciones sociales, primariamente, y las acciones de sus representantes, secundariamente, son sometidas a valoración. Obviamente, ello implica vigilar la actuación del Estado, pero también las actuaciones de otras instituciones sociales (verbigracia, partidos políticos o instituciones globales como el Fondo Monetario Internacional) que inciden marcadamente sobre asuntos esenciales de la vida humana. La moral crítica contenida en los derechos humanos no sirve exclusivamente como criterio para juzgar el actuar de instituciones sociales y sus representantes, pues la moral crítica trae consigo la idea de que los derechos humanos son instrumentos útiles y legítimos, a los fines de exigir la modificación o eliminación de instituciones y prácticas que contradicen o lesionan dichos 
derechos. Entonces, el carácter moral crítico de los derechos humanos también es apto para pedir legítimamente la constitución de instituciones y mecanismos que sean compatibles con ellos y que garanticen su efectiva aplicación ${ }^{71}$.

Para hacer posible la eficacia de los derechos humanos en tanto derechos morales es, pues, necesario que ellos sean integrados como componente social fundamental, es decir, es menester que sean reconocidos como normas y derechos morales. Si este reconocimiento no se materializa, existe el peligro de que los derechos humanos pierdan su función normativa y que se limiten a tener única y exclusivamente una función crítica que podría reducirse a un campo estrictamente argumentativo. Aquí una palabra clave es el pasivo reconocidos, ya que con ello se da a entender que el reconocimiento social es constitutivo para la idea de los derechos humanos como derechos morales. La base de esta apreciación es que únicamente por medio del reconocimiento social pueden ser incluidos como elementos del sistema social en general. A ello se suma la circunstancia de que las sanciones morales que están englobadas en los derechos morales son legítimas en la medida en que éstos son reconocidos como instrumentos ciertos que han de regular la conducta de determinada manera. Si lo dicho se aplica a los derechos humanos, resulta que las sanciones morales que comprenden estos derechos en tanto derechos morales son vistas como legítimas cuando los derechos son reconocidos socialmente. Lo que aquí está en juego no alude simplemente a la legitimidad, también toca la efectividad de los derechos humanos: los derechos humanos serán más efectivos en tanto y en cuanto se considere que gozan de reconocimiento social.

Los derechos humanos, en virtud de que son derechos morales, son derechos en sentido estricto, pues sus titulares disponen de un sistema normativo que exige su respeto ${ }^{72}$. Ahora, los derechos humanos no tienen necesariamente a su servicio un sistema centralizado ante el cual se pueda demandar el respeto debido, sistema que además sería responsable de su aplicación, como es el caso de los derechos legales. Claro está que la diferencia básica entre ambos sistemas radica en que en el marco de lo jurídico-legal existe la posibilidad de

\footnotetext{
${ }^{71}$ John Rawls considera que la función crítica de los derechos humanos es un elemento determinante en el área del derecho internacional, lo que permite someter a evaluación la actuación de los llamados Estados criminales. Igualmente, el valor histórico de esta función crítica de los derechos humanos es destacado por Villavicencio. Véanse RawLS, John (2001): El derecho de gentes y una revisión de la idea de razón pública (Traducc. Hernando Valencia Villa, Barcelona, Paidós), pp. 93-96 y VILLAVICENCIO, Luis (2008): "¿Derechos humanos para quiénes? Reflexiones sobre algunas cuestiones embarazosas", en: Revista de Derecho (Volumen 21, № 2), pp. 45-47 y VILLAVICENCIO, Luis (2010): "El constructivismo kantiano según Rawls como fundamento de los derechos humanos", en: Frónesis. Revista de Filosofía Jurídica, Social y Política (Volumen 17, № 1), pp. 24-25.

72 Véase una posición similar en SteIner, Hillel (2006): "Moral Rights", en: coordinador David Copp, The Oxford Handbook of Ethical Theory (New York, Oxford University Press), p. 461.
} 
emplear la fuerza de manera legítima, para así conseguir el respeto y aplicación de los derechos, algo que no sucede en el sistema normativo moral. Mas con esto no se pretende decir que la fuerza está totalmente excluida de la moral, pues de hecho se presentan casos como, por ejemplo, el de la defensa propia, donde el uso de la fuerza está moralmente legitimado. No obstante, el uso de la fuerza no es un recurso primario de los derechos morales. El punto que se quiere destacar es precisamente que la fuerza, a efectos de lograr el respeto de los derechos humanos, vistos como derechos morales, no es algo ni prioritario ni constitutivo, puesto que el sistema normativo moral dispone de un sistema de sanciones que son efectivas, sin la necesidad de emplear la fuerza. Con esto se ratifica el sentido moral, y no el legal, de los derechos humanos.

Con seguridad el sistema normativo moral -al menos teóricamente-garantiza el alto grado de efectividad que requiere la aplicación de los derechos humanos, aunque ello no es argumento de suficiente peso para descartar ab initio la posibilidad de echar mano del sistema legal, de tal manera que es conceptualmente aceptable apelar a otros medios que permitan aumentar la efectividad de estos derechos. En ese sentido, la juridificación de los derechos humanos puede significar un aporte positivo, porque ello comporta tener el uso de la fuerza a disposición de los mismos, lo que conlleva tener la posibilidad de coaccionar a los obligados para que cumplan los deberes que se constituyen sobre la base de estos derechos, en caso de que no lo hagan voluntariamente. La existencia de los llamados derechos fundamentales y de múltiples pactos y tratados sobre esta materia, por medio de los cuales los Estados se comprometen a respetar los derechos humanos y a someterse a ciertas instancias no nacionales, es una prueba de que esta idea no es una simple hipótesis, sino una realidad. Los derechos humanos deberían concebirse como derechos de naturaleza moral, los cuales pueden ser juridificados, sin que ello implique la pérdida de su esencia moral. En ello reside justamente la afirmación de que los derechos humanos son prejurídicos.

Por supuesto, la pregunta obligatoria es si la juridificación de los derechos humanos es un deber, como lo sostiene la posición rigurosa. Para algunos autores como Thomas Pogge y Georg Lohmann, aquí no estamos en presencia de un deber; más bien se trataría de un actuar que encierra una ventaja: es ventajoso que los derechos humanos sean juridificados, ya que por esa razón dispondrán del uso de la coacción, lo que redunda en que la posibilidad de su realización sea mayor ${ }^{73}$. Usando términos kantianos, se diría que no se trata de algo categórico, sino hipotético. Sin embargo, no sería aventurado decir

${ }^{73}$ Véanse Lohmann, Georg (1998): "Menschenrechte zwischen Moral und Recht", en: coordinadores Stefan Gosepath y Georg Lohmann, Philosophie der Menschenrechte (Frankfurt del Meno, Suhrkamp), p. 98 y PogGe, Thomas (2011): Weltarmut und Menschenrechte (Berlin/New York, De Gruyter), p. 62. 
que en la medida en que existe el deber moral de asegurar el respeto y la promoción de los derechos humanos, igualmente en esa medida existe el deber moral de aplicar todos los medios que son política y moralmente legítimos para alcanzar ese objetivo. Este deber alude naturalmente a la juridificación de los derechos humanos. Pero no se está hablando de un deber primario, como en el caso de la posición rigurosa; lo que se tiene en mente realmente es un deber secundario. El deber moral primario consiste sencillamente en respetar los derechos humanos y, consecuencialmente, aplicar el sistema normativo moral y las correspondientes sanciones de las que éste dispone. Una vez traducidos los derechos humanos en derechos legales, el cumplimiento de éstos pasa a ser algo moralmente prioritario, amén de la prioridad que la práctica jurídica les debe dar. Materializar el respeto de los derechos humanos está supeditado en gran medida a la circunstancia de aceptar y cumplir tanto con el deber primario como con el secundario que han sido mencionados.

\section{A manera de conclusión}

En las diferentes secciones de este estudio se ha expuesto y analizado un punto específico de la relación existente entre los derechos humanos y la moral: la concepción de los derechos humanos en tanto derechos morales. Hemos visto que hay oposición a esta manera de entender los derechos humanos, aunque, no obstante, tal oposición (básicamente representada por Habermas) tiene el principal defecto de no ver que la moral sí es un sistema eficaz para regular la conducta humana, y cuyo objeto principal es lo colectivo. Por su parte, quienes sostienen que los derechos humanos son derechos morales coinciden conceptualmente en que el punto de partida es la moral, pero sus elaboraciones teóricas presentan marcadas diferencias. Lo que se quiere resaltar aquí es que tanto la concepción modesta como la rigurosa, ambas partidarias de la naturaleza moral de los derechos humanos, están afectadas por ciertas deficiencias. La primera no parece dar suficiente importancia al hecho de que la moral es un sistema social, por lo que minimiza la labor humana creativa de forma un poco arbitraria, al decir que los derechos humanos no necesitan en ningún caso de reconocimiento social. La posición rigurosa, por el contrario, da tanta importancia al elemento social, que postula la obligatoria juridificación de los derechos humanos, alejándose de la naturaleza moral de estos derechos. Al mismo tiempo, pareciera legitimar la existencia del Estado en base a la necesaria aplicación de los derechos humanos, pasando por alto que los derechos humanos son precisamente un límite o remedio al poder del Estado.

Las deficiencias conceptuales de ambas posiciones dan lugar a que sea necesaria una revisión y reformulación general de la noción de derechos humanos en tanto derechos morales. La cuarta sección presenta un intento de comprender los derechos humanos en su faceta moral, asumiendo las fortalezas de las dos 
concepciones cuestionadas e incluyendo algunos elementos nuevos. Lo allí presentado es, por supuesto, una especie de bosquejo, algo que necesita mayor profundización, aunque parece ser una ayuda o aporte válido para iniciar un camino que necesariamente se debe transitar.

Más allá de las fortalezas y debilidades que muestren las dos perspectivas aquí examinadas, y más allá también de que ambas tesis puedan ser reelaboradas y superadas por visiones afines, tal vez lo más resaltante es el hecho de que se ha mostrado que sí es posible elaborar construcciones teóricas sólidas-aunque no perfectas- en favor de las ideas que defienden una visión no legalista de los derechos humanos. Aquí no se pretende reprobar al derecho positivo. Lo que se quiere es hacer hincapié en la idea de que el concepto de los derechos humanos pertenece esencialmente al campo extrajurídico. Si se asume un criterio diferente, perderíamos una herramienta teórico-práctica que, mal que bien, ha permitido legitimar determinados reclamos que política y moralmente son justificados, aunque legalmente puedan ser desechados. Visto así, ciertamente se trata de teorías, pero su fin último no es la simple disquisición intelectual, sino trascender hacia el campo de la práctica. 